\title{
Press Data and Information Graphics, Prospects and Challenges of Development in the Arab World
}

\author{
Hyder Abdelhafeez Mohammed ${ }^{1}$, Nahid Alamin Ibrahim ${ }^{2}$ \\ ${ }^{1}$ Media Department, Faculty of Arts Red Sea University, Port Sudan, Sudan \\ ${ }^{2}$ Languages Department, Ahlia College, Port Sudan, Sudan
}

Email address:

hydermammd@yahoo.com (H. A. H. Mohammed), Nahidibrahim7272@gmail.com (N. A. Ibrahim)

\section{To cite this article:}

Hyder Abdel Hafeez Mohammed, Nahid Alamin Ibrahim. Press Data and Information Graphics, Prospects and Challenges of Development in the Arab World. American Journal of Computer Science and Technology. Vol. 2, No. 4, 2019, pp. 48-51. doi: 10.11648/j.ajcst.20190204.11

Received: May 15, 2019; Accepted: October 14, 2019; Published: December 23, 2019

\begin{abstract}
The Researcher aimed to studyData Journalism development of horizons and challenges in Arabworld, Research study applied to a sample of contents of 2 Arab Newspaper (Emarat Alyoum \& Al- jazirah Sudai Newspaper) 47 topics for Emarat Alyoum and 46 topics for Al- jazirah forall contentsuntilthe date of15 November 2016. The researcher's sense of the problem came from Challenges and difficulties facing by the data journalism in Arab World and stopped it progress. The researcher has used the descriptive analytical approach as a way of releasing on a compilation of facts and information compared and analyzed and interpreted to reach acceptable generalizations. The most important findings of the study:a- The top topics of data journalism in Arab World are Politics, Sport and economy. InEmarat Alyoumnewspaper the statistics show that 29,7\%.for sport topics, 12,7\% for Politic, for Economy, Al- jazirahSudanese newspaper statistics shows that $17.7 \%$ for Politics topics, 13.1\% for Economy, and 10,9\% for sport topics. b- The weak interest of data journalism in the Arab world regardtosocial and scientific topics, whereas the social topics in EmaratAlyoum newspaper reach to2.2\%and it didn't receive any social topics in Al-jazirah, newspaper, according toscientific topics Emarat Alyoum newspaper, didn’t receive any scientific topic for data journalism during the $21.3 \%$. The study find that data journalism in Arab world depends much on the international resources so in [Emarat Alyoum] local newspapers find the percentage of the international resources reach to $74.5 \%$ whereas the local recourses reach to $25.5 \%$, and in Al-jazirah newspaper the international resources reach to $63.9 \%$ and the local resources reach to $36.1 \%$, that means the international content more than the local Arabic content. The most important Recommendations are: 1- Arab worldshouldcare about data journalism and providing Human and financial potential, which necessary to success and develop the data journalismin Arab world. 2- The Enrichment of the digital content with data and information in all domains and topics, and make Arabic work plan for the sake of realization thepurposes.3-The training of technicians and journalists in field ofdata journalism, to raisetheir technical and journalistic skills.4- Encourage the Arabian investment in this data journalism field, and thegovernments offer the neededfacilities.
\end{abstract}

Keywords: Data, Journalism, Information Technology Newspaper, Challenges

\section{Introduction}

The recent development of the press through the use of computers and the Internet has been followed by an evolution in content. After the data and graphics were limited to the art of writing a journalistic survey, the employment of data is through a new term called information journalism. Among these are the data obtained, revised, Draw graphics, images, and graphic formats in a streamlined but in-depth content that is attractive to readers. The press has become an audience of journalists and journalists. In our fast-paced era, readers like to get what they want from news and press material without having to read the data press much of the time, and in our Arab world, after the West in this type of journalism, In this type of press, but it faces great challenges for its development.

\subsection{Research Problem}

The researcher's sense of the problem came through the recognition of the challenges and obstacles that stand in the 
way of the use of data journalism and employment in the Arab world.

\subsection{Research Questions}

The researcher seeks through studies to answer the following questions:

What is the reality of data journalism in the Arab world?

What are the most important challenges of the press in the Arab world?

What are the topics covered by data journalism in the Arab world?

What are the sources of data journalism in the Arab world?

What are the material highlighting and influencing the data press in the Arab world?

\subsection{Research Goals}

As the research aims to achieve, so the study seeks to the main objective arising from the main question to identify the reality of data journalism in the Arab world, through the experiences that are in the Arab world to stand on and studies; Providing a press service for readers in the Arab world.

\subsection{The Significance of the Research}

The importance of research stems from the fact that it constitutes a basis that can open the door for more scientific research in the field of data journalism. This type of research helps practitioners and academics to learn how to benefit from research in the development of data journalism in the Arab world, which has become a reality today.

\subsection{Research Methodology}

The methodology used by the researcher to reach the target results The researcher adopt the analytical descriptive approach as a holistic approach; it is based on the compilation of facts and information and then comparing, analyzing and interpreting them to reach acceptable generalizations. The researcher uses a content analysis form for the content of data journalism in the Arab world.

\subsection{The Limitation of the Study}

The research was conducted on the content of the websites of Al Jazeera Saudi Arabia and UAE today until February 15, 2016 for the availability of electronic content in both sites under the category of (Info graphic).

Spatial framework:

Web sites for press data represented in the newspapers $\mathrm{Al}$ Jazeera Saudi Arabia and the United Arab Emirates today.

Information gathering tools:

\subsection{Methodology}

For content analysis. The researcher used the content analysis tool:

Is a tool and method for identifying information and interpretations

\subsection{Definition of Concepts and Terminology}

Press Release:

The language of the press means that the pages are published regularly on a regular basis and are collected by newspapers and newspapers. The most common terminology in the Arab world is that of Sheikh NajibJawad, the founder of the Arabic newspaper of San al-'Arab in Alexandria and the grandson of Sheikh Nasif al-Yaziji. Where she took a journalist.

Data: In the short lexicon, the object appears back and forth Al-Jazayz,(2006)

Data Journalism is a modern journalism created by the advent of the Internet and communication technology. The journalist was able to narrate any complex story through Info graphics for easy access to the Continental via annotations, graphic backgrounds, maps and pictures as needed in the journal article.

Informatics Fees:

Is a graphic design and presentation of data and information in the form of images, drawings, interactive maps, circles or diagrams that simplify the journalistic material and attract the continental to follow it to the extent that it affects it.

Previous Studies and Criticism:

The field of research in data journalism is modern compared to other fields of research in the press. Therefore, the research conducted in the subject is few due to the novelty of the topic, but the researcher used two studies:

The study of Jawahar Abdullah Farhan al-Afifi, on the behavior of searching for information among journalists in Okaz, focused on the study of Jawahar, which conducted through a survey method of the questionnaire, information and how to obtain it and study on the Kingdom of Saudi Arabia Okaz Foundation (Afifi, 2014, p. 5), While the researcher included the applied study the reality of data journalism in the Arab world through an analytical descriptive study aimed at identifying the most prominent challenges of this type of journalism with the identification of the topics and sources from which to extract data and information in the publication.

The study differed from Ismail's study with the research study in that the Ismail study focused on the search for information by the journalists in the field of information. The scope of the Sudan while the study of the researcher dealt with the reality of data journalism at the level of the Arab world.

\section{Methods}

\subsection{The Research Sample}

The researcher conducted a research aimed at analyzing the content of the information press on a sample of data press sites by selecting two Arabic websites for Al-Jazeera Saudi Arabia and Emirates today, as sites that specialize in data journalism, as well as content

Analysis of theStudy Data and Statistical Analysis2.2 
Table 1. Shows the data press issues for Emirates Today.

\begin{tabular}{llllllll}
\hline Category & Sports & Medical & Athlete & I disasters & economic & Astronomy & Environmental \\
\hline Repetition & 14 & 5 & 6 & 4 & 5 & 2 & 4 \\
Percentage & $\% 29.70$ & $\% 10.60$ & $\% 12.70$ & $\% 8.50$ & $\% 10.60$ & $\% 4.20$ & $\% 8.50$ \\
\hline
\end{tabular}

Table 1Continued.

\begin{tabular}{|c|c|c|c|c|c|c|c|}
\hline Category & Fashion & Technology & Women 's affairs & energy & Social & Mix & Total \\
\hline Repetition & 1 & 2 & 1 & 1 & 1 & 1 & 47 \\
\hline Percentage & $\% 2.20$ & $\% 4.20$ & 2.2 & $\% 2.20$ & $\% 2.20$ & $\% 2.20$ & $\% 100$ \\
\hline
\end{tabular}

It is clear from Table 1that the issues of data journalism in the newspaper were topped by sports by $29.7 \%$, due to the interest of the UAE newspapers in various sports such as football, European league news, FIFA tournaments, statistics of the last World Cup, Medicine and economics each with $10.6 \%$, followed by disasters, accidents and environmental issues at $8.5 \%$ each. The percentage of subjects of astronomy and technology was 4.2 for each, while the subjects of fashion, energy, social issues, women's affairs and miscellaneous were $2.2 \%$.

Table 2 Sources of data journalism for Emirates Today
Table 2. Sources of data journalism for Emirates Today World Category Arabic World Total.

\begin{tabular}{llll}
\hline Category & International & Arab world & Total \\
\hline Repetition & 35 & 12 & 47 \\
The ratio & $\% 74.50$ & $\% 25.50$ & $\% 100$ \\
\hline
\end{tabular}

Table 2 shows that the data sources of the newspaper dominated the global source by $74.5 \%$ and $25.5 \%$ respectively, which means that the data press in the Arab world is more than the producer of the data content.

Table 3. Shows the means of highlighting the data press for Emirates Today.

\begin{tabular}{|c|c|c|c|c|c|}
\hline Category & Illustrations & Photographs & photos Video & Geographic maps & Graph \\
\hline Repetition & 22 & 16 & 3 & 3 & 1 \\
\hline percentage & $46.80 \%$ & $34.10 \%$ & $6.40 \%$ & $6.40 \%$ & $2.10 \%$ \\
\hline
\end{tabular}

Table 3. Continued.

\begin{tabular}{llllll}
\hline Category & circles & numbers & Texts & Tables & Total \\
\hline Repetition & 1 & 1 & 0 & 0 & 47 \\
percentage & $2.10 \%$ & $2.10 \%$ & 0 & 0 & $100 \%$ \\
\hline
\end{tabular}

It is clear from Tale 3 that the means of highlighting in the subjects of data journalism were led by explanatory drawings which amounted to $46.8 \%$, followed by the photographic method by $34.1 \%$, the video images and geographic maps reached $6.4 \%$, while the percentages of the graphs, Each of them and the means of highlighting in the newspaper of the texts and the table, and the texts alone are not attractive as a means of clarification which made the newspaper using other means of clarification.

Table 4. The Journal of Journalism.

\begin{tabular}{llllll}
\hline Category & Politician & economic & environmental & Athlete & accidents \\
\hline Repetition & 8 & 6 & 6 & & migration \\
percentage & $17.40 \%$ & $13.10 \%$ & $13.10 \%$ & 5 & 5 \\
\hline
\end{tabular}

Table 4. Continued.

\begin{tabular}{|c|c|c|c|c|c|c|}
\hline Category & Technology & Tourism & Medical & Education & \& Scientific & Total \\
\hline Repetition & & 3 & 2 & 2 & 1 & 46 \\
\hline percentage & 3 & $6.50 \%$ & $4.30 \%$ & $4.30 \%$ & $2.10 \%$ & $100 \%$ \\
\hline
\end{tabular}

It is clear from Table 4 that the topics of data journalism in Al-Jazeera were topped by political subjects by $17.4 \%$, while the subjects of economy and the environment were $13.1 \%$, sports, accidents and migration accounted for $10.9 \%$, while technology and tourism accounted for $6.5 \%$ Science subjects ranked the most recent among the subjects at $2.1 \%$. The paper noted that the newspaper is less interested in science in the data press, especially that the field of science is rich in data and information that suits This type of press and hence His need for simplification, explanation and clarification through the means of highlighting used by the data press.

Table 5. Shows the sources of the data press for Al-Jazeera.

\begin{tabular}{llll}
\hline Category & International & Arab world & Total \\
\hline Repetition & 29 & 17 & 46 \\
The ratio & $63.10 \%$ & $36.90 \%$ & $100 \%$ \\
\hline
\end{tabular}

Table 5 lists the world's leading data sources as $63.1 \%$ and $36.9 \%$ respectively. This indicates that data journalism in the Arab world is more than a producer of data content 
Category Maps Geography Illustrations Figures Photos Diagrams Tables Texts Images Video Total

Table 6. Shows the means of highlighting the data press for Al-Jazeera.

\begin{tabular}{lllllllllll}
\hline Category & Geography maps & Illustrations & numbers & Photographs & Graph & circles & Tables & Texts & photos Video & Total \\
\hline Repetition & 12 & 10 & 8 & 7 & 6 & 2 & 1 & 0 & 0 & 46 \\
Percentage & $26.10 \%$ & $21.70 \%$ & $17.40 \%$ & $15.20 \%$ & $13.10 \%$ & $4.30 \%$ & $2.20 \%$ & 0 & 0 & $100 \%$ \\
\hline
\end{tabular}

It is clear from Table 1 that the means of highlighting the newspaper topped by geographical maps $26.1 \%$, as the newspaper is keen on the various topics to use geographical maps of the clarification and is a way to highlight the impact on readers, especially in comparisons that take the nature of spatial and geographical, and the proportion of the use of illustrations Illustration 21.7, The newspaper used the figures as a means of highlighting $17.7 \%$, the photographs were $15.3 \%$, the graph by $13.1 \%$ and the circles by $4.3 \%$ and the table was $2.2 \%$ and the newspaper was free of means to produce texts and video images.

\section{Results}

The study found the following results:

A-Politics, sports and the economy dominated the contents of the data press in the Arab world. The sports subjects in the Emirates newspaper reached $29.7 \%$, the policy was $12.7 \%$ and the economic $10.6 \%$. In Al-Jazira, the political issues were $17.4 \%$, economic $13.1 \%$, sports $10.9 \% \%$.

B - The lack of interest in data journalism in the Arab world, social and scientific topics, where the subjects of the meeting in the newspaper today, the proportion of $2.2 \%$, and did not respond to any social topics in the newspaper, or the scientific issues, the newspaper did not report today any scientific subject of the data press during the study period, While the percentage of science subjects in Al-Jazeera newspaper was $2.1 \%$.

C-The survey revealed that data journalism in the Arab world is highly dependent on global sources. In the United Arab Emirates today, the percentage of global sources is $74.5 \%$, while domestic is $25.5 \%$. In Al-Jazeerah, $63.9 \%$ and $36.1 \%$ are global sources. It is more universal than local Arab content.

d - Data journalism in the Arab world used various means of highlighting such as: geographical maps, illustrations, figures, photographs, graphs, circles, tables, and video images. The illustrations topped the data press in the Emirates today by $46.8 \%$, while geographical maps lost the leading means of highlighting the newspaper Al Jazeera by $26.1 \%$.

\section{Conclusion and Recommendations}

1. interest in data journalism in the Arab world and provide the necessary material and human resources for the success and development of data journalism in the Arab world.

2. To enrich the digital content with data and information in various magazines and subjects, and to develop an Arab plan of action in order to achieve this purpose.

3. Training of technicians and journalists working in the field of data journalism and raising their abilities and technical skills and journalism.
4. Encourage the Arab capital to invest in this field and provide the States with the necessary facilities.

5. the need to rely on Arab content and Arab sources in order to benefit the Arab communities of the content of the press data of the Arab world.

6. The allocation of sections in the paper and electronic newspapers of the Arab press data in a form and content competing with the international data press.

7. The importance of data journalism in the Arab world to the social and scientific subjects, because of the usefulness of societal topics in the development and progress of societies What is important is the presentation of scientific subjects to suit the forms of data journalism because they need explanation and simplification.

\section{References}

[1] Amir Ibrahim (2015) Scientific research in the press and media. Dar Al Masirah for publication, distribution and classificationOman.

[2] Abu Bakr (2014) Data Press Directory Translated Version. Cairo: Egyptian Book House.

[3] Abdullah, Mokhtar (2009), the electronic network and its impact on the development of the Sudanese press. Master Thesis. Khartoum: University of Khartoum. Faculty of Arts.

[4] Abdel Baqi Ismail, (18-21 December 2011) The Behavior of Searching for Information for Sudanese Journalists, Paper presented to the 22nd Conference of the Library and Information Union. Sudan.

[5] FarhanAl-Afifi, Jawahar (2014) Behavior of information search for journalists at Okaz Foundation. Search Master. Riyadh. King Abdulaziz University. Faculty of Arts and Humanities.

[6] Hussein, Mohamed (1995) Media Research. I. Cairo: World of the Book.

[7] Jacobs. A., (2009). The pathologies of bis data. Communication: of the ACM. 52(8), 30.

[8] Kanaan, on (2015) electronic media. Oman: Dar Al Ayam for publication and distribution.

[9] Kraska. T. (2013). Finding the needle in the big data svstems haystack. IEEE Internet Computing. 1. S4-S6.

[10] Mahjoub, Wagih (2005) The origins and methods of scientific research. Amman: Curriculum House.

[11] Mohammad, Samir (1996) Analysis of content, definitions, and methods. Cairo: World of the Book.

[12] Mohammad Shakir, (2015) Data Journal How to extract news from the piles of numbers and information from the Internet. Translated book. Doha: Qatar's Al-Jazeera TV. 